\title{
The Exterior Decorations on the Inner coffin of PA-dj-jmn in Cairo Museum (CG 6082 and CG 6079) and the Judgment of the Dead
}

\author{
Eltayeb Abbas \\ Youssri Abdelwahed \\ Minia University
}

\begin{abstract}
This paper deals with the exterior decorations and texts on the inner coffin of PA-dj-imn in Cairo Museum as representation of the Judgment of the Dead. Scenes on the lid of the coffin will be related to the ritualized Judgment of the Dead, while the case decorations will be considered as representation of the Hall of the Judgment. Scenes will be arranged in a sequence and will be dealt with as a single unite. The inner coffin of PA-di-imn dates to the reign of the High Priest Pinudjem II. Recently Niwiniski has provided a primary publication of the coffin in Cairo Museum. ${ }^{1}$
\end{abstract}

Keywords: coffin, rituals, judgment, death, resurrection, dead

\section{The lid of the inner coffin in Cairo Museum (Fig.1)}
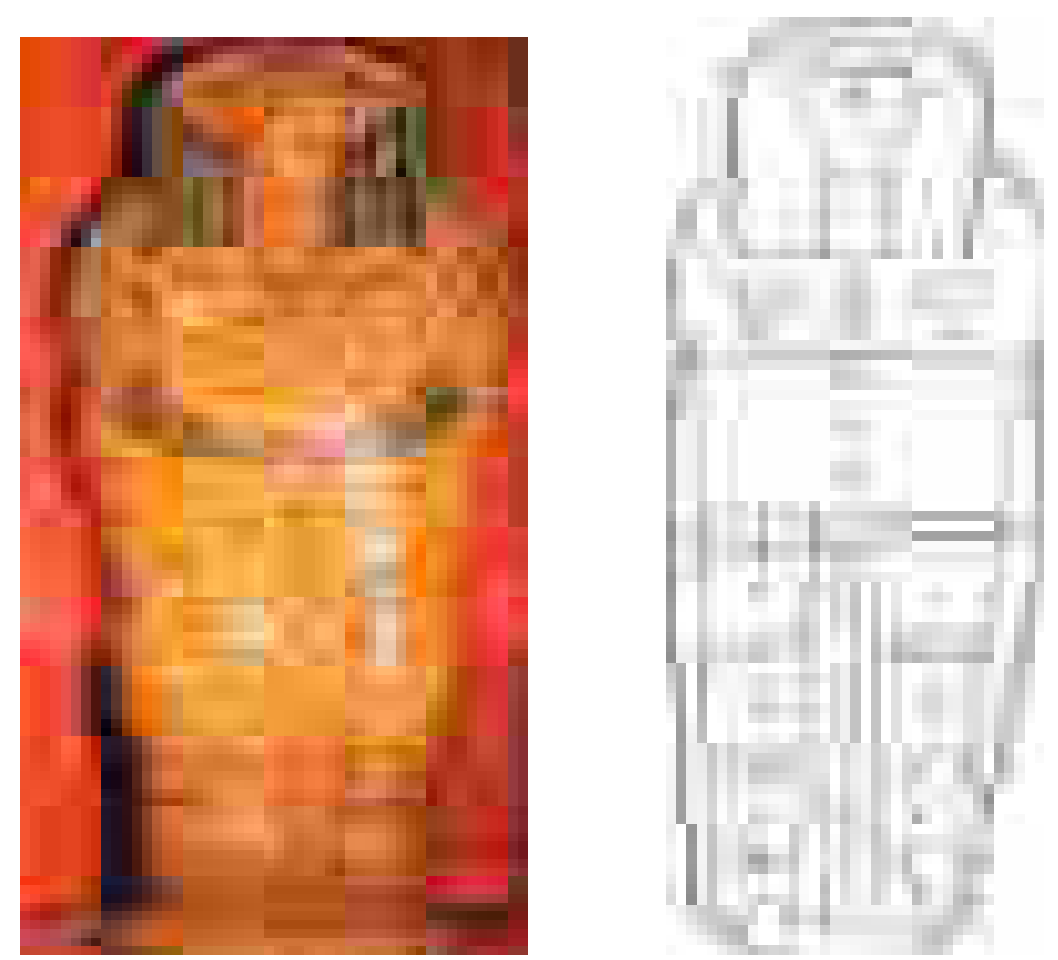

Figure (1): The lid of the inner coffin of PA-dj-jmn (photograph courtesy of the Egyptian Museum in Cairo) and a drawing by the authors showing the distribution of the scenes and texts on the lid

The lid of the inner coffin of PA-dj-jmn is made out of wood covered with plaster. The scenes are multicoloured and then painted. ${ }^{2}$ The deceased face is framed by a stripped tripartite wig. A single band necklace with a hanging collar surrounds the throat. The central part of the collar between the clenched hands carries figural decorations in four registers, as follows; ${ }^{3}$

(A 1) The lowest register shows the resurrected Osiris lying on a funeral bier. Nephthys and Isis are shown sitting respectively in a gesture of mourning before and behind the bier. Osiris is shown with royal signs wearing a crown, and a cobra on the forehead. The bier is designed in a bed form with lion's legs and tail. Beneath the bier there are several crowns and headdresses.

(A2) Below the two crossed forearms, are two small squatting deities protected by two falcons with sun discs on their heads and two cobras. The two falcons with wDAt eye appear on many cartonage cases and coffins of the $21^{\text {st }}$ Dynasty and also on coffins of the 22-25th Dynasties. ${ }^{4}$ Sometimes, they represent Selkis and Neith, Horus of Behdet, or Nephthys and Isis. On the lid of the inner coffin of PA-dj-jmn, it is not clear how to read the names of the two falcons. By comparing the speeches of Neith and Selkis on the lid two borders - as will be seen below-, the two falcons might 
represent the two goddesses and they complement the roles of Isis and Nephthys, who are shown at the bier's head and feet. Their outstretched wings convey protection as well as wafting air to the deceased Osiris. ${ }^{5}$

(A 3) The second register is occupied by a falcon, protecting the mummy of Osiris. Above the falcon's shoulder, two lions' heads emerge and on both sides of the falcon's wings there are two wDAt eyes with anx sign attached to its wings.

(A 4) The third register shows a solar barque with a seated mummiform figure with a falcon head, and a solar disc with cobra on the forehead and two crooks (Gardiner sign list T. 18). Osiris name is written in front of the seated figure, exactly, above what seems to be a small shrine. The boat is flanked by two cobras with sun discs on their heads designated as Neith and Selkis.

(A 5) The fourth register above the solar barque shows a winged scarab surmounted by a solar disc with two descending cobras. The scarab is protected by two winged cobras with two wDAt eyes. ${ }^{6}$

\section{The Middle Part of the Lid}

This part is divided into two registers by the figure of the sky goddess Nut. The first register is the section above the goddess and the second is beneath her wings.

(B1) The lid's central part is occupied by the figure of the sky goddess Nut with her outstretched wings and arms in a gesture of protection, and wears a vulture headdress. The face of Nut is turned left, and goes with the text on the lower part, where the deceased is addressing her to spread her wings over. In the first register above Nut, there is a pectoral with a scarab in the middle flanked by two falcons residing on a Hb sign and escorted by a cobra. The scarab and the two falcons have solar discs with cobras. On both sides of the pectoral, there are three sacred emblems depicted. An emblem with head of a jackal on the top, another similar one with falcon head, and the third is the emblem of Abydos.

Behind the wings of Nut, there is a scene on each side arranged in three registers. The upper left register shows a personification of horizon kneeling in adoration gesture before the squatting mummiform figure of Osiris. The second register shows bA standing in adoration gesture with the name of Osiris written in front. The third register shows three of the four sons of Horus - Qebehsenuef, Hapi and Duamutef- in squatting mummiform. The scene on the right side is almost identical, except the third register, where Duamutef is only depicted.

(B 3) The second register is divided into three scenes. The central scene shows a barque with a shrine above. Before the barque there is a net with a bird on its top. There are two adoring apes sitting on the shrine's two sides, where Osiris name is written in a small caption as anx wsjr xntj. Above the shrine, there is a scarab with a sun disc and two cobras. The solar disc is bordered by two small squatting figures in adoration gesture. The scarab and the squatting figures are bordered and protected by two winged cobras.

On both sides of the middle scene, there are two identical scenes of the deceased, making libation before a seated figure of Osiris Foremost of the Underworld (wsjr xntj dwAt). Osiris is seated on a throne with two steps platform and accompanied by the imy-wt. In front of Osiris there is an offering table with a bA bird flying over it. PAdj-jmn is making libation in front of Osiris, while water comes out from a vessel on the offering table. Above PA-djjmn is a small text, while he pours water from the vesseThetis text reads as follows;

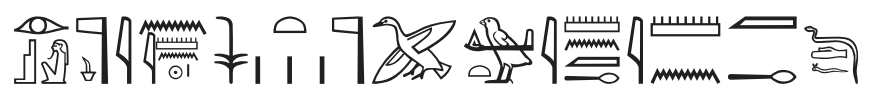

wsjr jt nTr jn jmn-ra nswt nTrw pA-dj-tw-jmn mAa-xrw Dd=f

Osiris God's Father of Amun-Re King of the Gods PA-dj-jmn the Justified he says....

\section{The Lower Part of the Lid}

The lid's lower is divided into two symmetrical parts by three columns of inscriptions running down to the feet. These columns -from left to right- read as follows; 
1

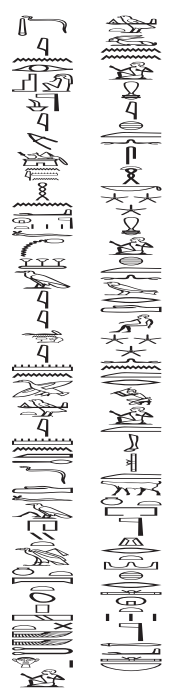

2

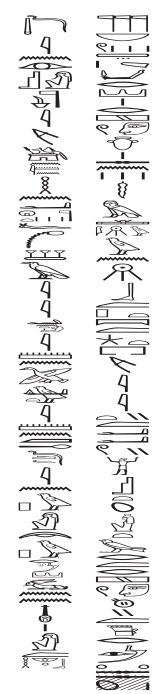

3

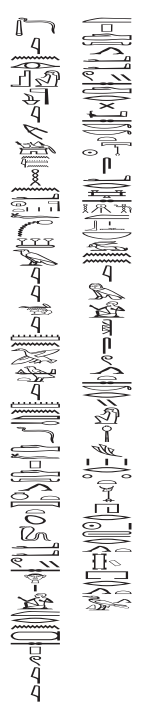

\section{(1) The left column}

Dd mdw jn wsjr-jt-nTr-mrj-Hry-sStA-n-jmn-Hna-psDt-f-wab-SAj-n-HAt-jmn-pA-dj-tw-jmn mAa-xrw Dd=f hAj mwt nwt $\mathrm{pS}(\mathrm{t}) \mathrm{dbHwj}=\mathrm{T} \mathrm{Hr}=\mathrm{j}$ dj.tw wnn=j mj jxmw skw mj jxmw wrDw nn mwt=j m wHm m-Xnw Xrt-nTr xr psDt aA nb Speech by Osiris, the God's Father, the Beloved, Keeper of the Secrets of Amun and his Ennead, the First Prophet in front of Amun PA-dj-jmn the Justified, may he say (Oh) mother Nut may you spread your wings over me, and make me exist like the Imperishable Stars and the Unwearying Stars, so that I will not die again in the necropolis near the Great Ennead ruler of......

\section{(2) The middle column reads:}

Dd mdw jn wsjr-jt-nTr-mrj-Hry-sStA-n-jmn-Hna-psDt-f-wab-SAj-rmn-HAt-jmn-pA-dj-tw-jmn mAa-xrw Dd=f (j) jnpw jaH pw r mAnw wnn-nfr m Hb nTrw nbw tA Dsr rSw jb-sn nDm Sw wbn m pt m dwAt mrytj m (H)aawj Ast wr(t) $\mathrm{m} \mathrm{rSw}$ m-Dr mAA=sn sA////////////

Speech by Osiris, the God's Father, the Beloved, Keeper of the Secrets of Amun and his Ennead, Designated Priest, Front-bearer of Amun, PA-dj-jmn the Justified, he says: Anubis, you Moon at Manu (mountain), Wenennefer is in festival, all the gods of the necropolis rejoice and their hearts are happy, Shu who shines in the sky and in the Netherworld, the beloved, is in joy, and great Isis is in joy, when they see the son.

\section{(3) The right column reads:}

Dd mdw jn wsjr-jt-nTr-mrj-Hry-sStA-n-jmn-Hna-psDt-f-wab-SAj-n-HAt-jmn-pA-dj-tw-jmn mAa-xrw Dd=f pd nwt awj=s Hr=j m rn=s pwy m pd awy=s dr=s kkw sar.s Hddwt m bw nb wnn.j jm (m) Sms skrj HD jrtj(?) hrw pXr jnb prt $\mathrm{aq}$

Speech by Osiris, the God's Father, the Beloved, Keeper of the Secrets of Amun and his Ennead, Designated Priest, Front-bearer of Amun, PA-dj-jmn the Justified, he says: May Nut spread her arms over me in this her name of She Who Spreads Her Arms. May she drive away darkness and brings up light in every place I am in, (in) the following of Sokar, Bright of Eyes, on the Day of Going Around the Wall, emerging and entering ...

The scenes on both sides of the lid's lower part are composed of four registers. The first three scenes are depicted within a naos shaped frame, and preceded by a horizontal band of inscriptions written vertically. These scenes on the left and right sides - each composes of two levels- are identical. The scenes run as follows:

\section{The First Register}

This register's upper level has three seated figures of Horus sons Qebehsenuef, Hapi, and Duamutef. In front of them, there are offerings and a Dd pillar, and behind is a similar pillar. On the lower level, a squatting image of Osiris depicted on a raised platform. In front of Osiris, two kneeling men are holding ceremonial staff in their hands. The horizontal inscriptions - written vertically- above the first register, reads;

(4) On the left, the text reads;

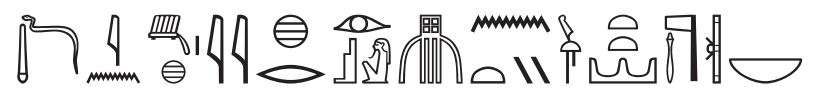


Dd mdw in jmAxj xr wsjr xntj-jmntt nTr aA nb

A speech by the Revered One with Osiris Foremost of the West, the Great God, and the Lord

(5) On the right the text reads;

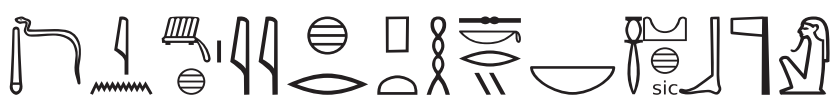

Dd mdw jn jmAxj xr ptH-skr nb AbDw

A speech by the Revered One with Ptah-Sokar, Lord of Abydos

\title{
The Second Register
}

(D) The upper section of this register has the image of a sphinx wearing the double crown, and a falcon outstretched wings protects from behind. In front of the sphinx, Maat is depicted squatting in a mummiform figure. The sphinx is described as wsjr xntj jmntt 'Osiris Foremost of the West'. The lower register shows a goddess seated between the two emblems of the west. She is depicted with upraised and outstretched arms holding anx signs. The texts on the left and right sides read;

(6) On the left the text reads;

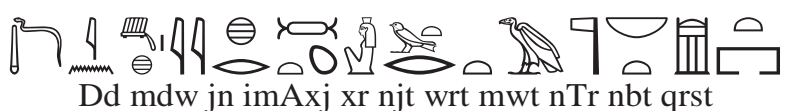

A speech by the Revered One with Neith the Great, Mother of the God and Lady of the Tomb.

(7) On the right, the text reads;

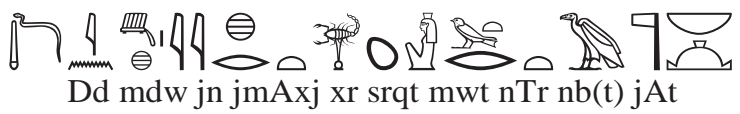

A speech by the Revered One with Serqet, Mother of the God, Lady of the Mound

\section{The Third Register}

(E) This register has a scene of a sacred bull described as nTr aA nb pt (the Great God, Lord of the Sky). Before the Bull, there are offerings and a small squatting figure of Isis. The bull carries a solar disc surmounted by two feathers on his head. Above the bull are signs of royalty, and the emblem of the west is behind. Above the bull at the far end is a wDAt eye with an anx sign. The whole scene is surmounted by a vault with two cobras and a falcon's head emerging from. The text above this register reads;

(8) On the left

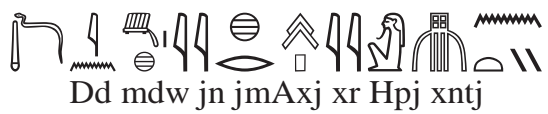

A speech by the Revered One with Hapi, Foremost of...

(9) On the right

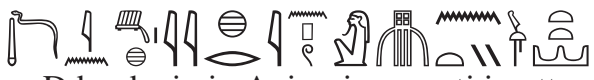 \\ Dd mdw jn jmAxj xr jnpw xntj jmntt \\ A speech by the Revered One with Anubis, Foremost of the West
}

The falcon and the bull with sun discs may have dual meaning; they might represent the sun god at morning emerging from the underworld or the realm of Osiris and bringing regeneration. It might also represent the deceased as a bull of the sky -a well known theme in the Pyramid Texts, where in a spell Unas is designated "the Bull of the sky, aggressive in his nature"-, 7 which also refers to the juxtaposition of the sun god and Osiris. This alludes to the union of the two divinities, which was crucial and rejuvenating event of the solar deity's nocturnal passage through the netherworld. ${ }^{8}$

\section{The Fourth Register}

(F) This scene is inverted and carries a representation of a goddess, kneeling on the sign of nbw. She sits in front of Abydos emblem and an emblem with the sacred falcon in adoration gesture. The text above this register reads;

(10) On the left side, the text reads;

Dd mdw jn jmAxj xr Hapj xntj

A speech by the Revered One with Hapi, Foremost 
(11) On the right side, the text reads;

Dd mdw jn jmAxj xr gb nb jmntt

A speech by the Revered One with Geb Lord of the West

\section{The Decorations and Texts at the edge of the Feet}

Two vertical inscriptions run in the opposite directions towards the feet edge.

(12) The inscription on the left side, reads;

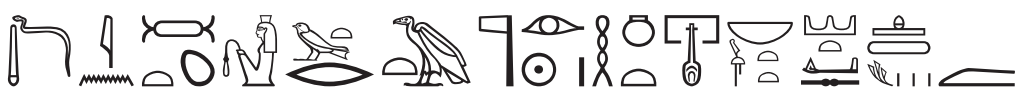

Dd mdw jn njt wrt mwt nTr jrt Ra Hnwt pr-nfr nbt jmntt $\mathrm{dj}=\mathrm{s}$ Htpw m

A speech by Neith the Great, Mother of the God, Eye of Re,Mistress of the Beautiful House and Lady of the West, that she may give offerings of ....

(13) The inscription of the right side, reads;

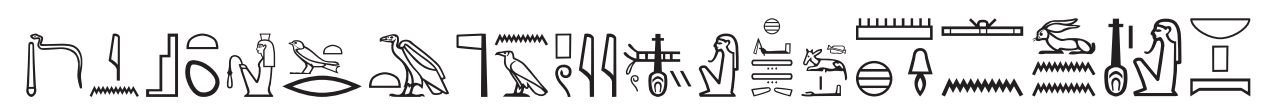

Dd mdw jn Ast wrt mwt nTr nA pwj Nfr-tm xwj tAwj jwa mnx n wnn-nfr nb p(t)

A speech by Isis the Great, Mother of the God: This is Nefertem who protects the two lands, the potent heir of Wenennefer, Lord of the Sky

\section{The Texts on the lid Borders}

On both sides along the lid edge, there are two vertical columns of text running below the elbow and down the feet.

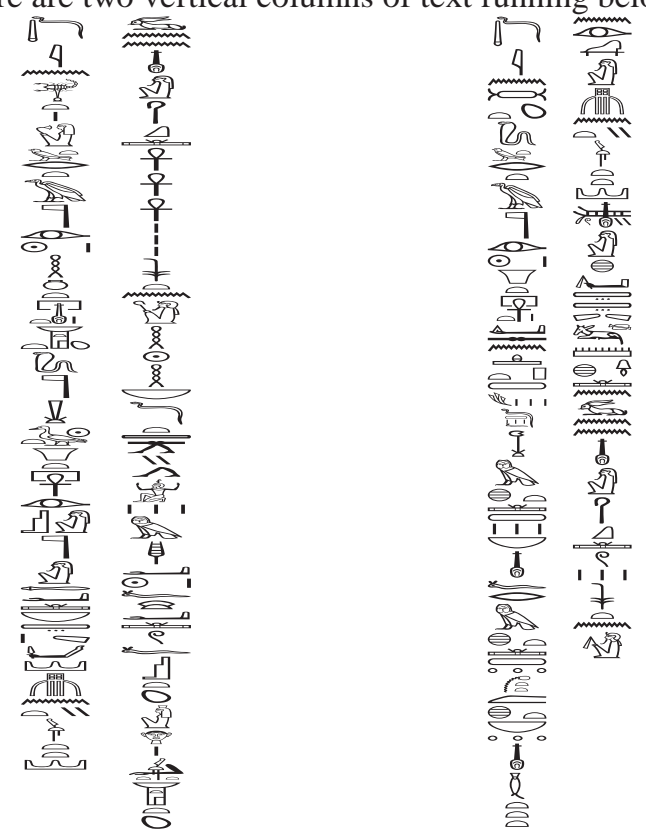

(14) The column on the left reads;

Dd mdw jn srqt wrt mwt nTr jrt ra Hnwt pr-nfr nbt-Hwt snt sAt ra Hnwt pr-anx wsjr nTr aA nb tA-Dsr xntj-jmntt wnnnfr HqA anxw nswt nHH nb Dt sbj HHw m aHa.f xaw=f Ast Hr imntt nbt Hwt

A speech by Great Serqet, Mother of the God, the Eye of Re, Mistress of the Beautiful House, and Nephthys sister-daughter of Re and Mistress of the House of Life: Osiris the Great God, Lord of the Sacred Land and Foremost of the West, Wenennefer, Ruler of the Living, King of Eternity and Lord of Everlasting, who passes millions with Re in his lifetime, he appears with Isis on the west and Nephthys .......

(15) The column to the right reads;

Dd mdw jn njt wrt mwt nTr jrt Ra Hnwt pr-anx dj=s\{n\} Htpw DfAw XA m xt nbt nfrt m xt wabt m xt nfrt bnrt $n$ wsjr xntj-jmntt nfr-tm xwj tAwj jwa mnx n wnn-nfr HqA <anxw> nswt 
A speech by the Great Neith, Mother of the God, Eye of Re, and Mistress of the House of Life, that she may give offerings and sustenance, a thousand of every good thing and every pure thing, and every good and sweet thing to Osiris, Foremost of the West, Nefertem who protects the Two Lands, the potent heir of Wenennefer, Ruler of the Living and King of .......

\section{The Judgment of the Dead}

In the Coffin Texts, the ceremony of the Judgment of the Dead occurred at the end of the embalming ritual. The night before burial was concluded with awake that was celebrated with offerings, libations, censing, purification, and, most importantly, the recitation of ritual texts. These recitations confront us with the concept of the Judgment of the Dead, which was based on a royal model of the mythic lawsuit between Horus and Seth. According to the myth, Osiris was vindicated against Seth, and thus became the king of the netherworld. While Horus -the legal heir of the throne of his father Osiris- became the king of Egypt. The ordinary deceased would go through the same cycle of events as those occurred for Osiris. He would be vindicated against Seth-death and becomes one of the followers of Osiris. The deceased bears the same titles of Osiris along with his own name, titles, and epithet of being mAa-xrw (Justified or Vindicated), or jmAxj (Revered One). ${ }^{9}$ In ancient Egypt the deceased faced two kinds of death, the first is caused by Seth who has dismembered his body and isolated him from his family. The deceased Osiris could be cured from this death by the combined efforts of Isis, Nephthys, Horus, Anubis, and Thoth. After the great efforts of these deities, the deceased's body is reassembled and with this the deceased Osiris has escaped the first death, but Seth continued threaten the deceased even after having been vindicated. He continued to threaten his offerings with annihilation, and which is described by Assmann as the second death. For that reason, Seth had to be confronted, humiliated, and punished. All these acts were done to Seth in the ritual of the Judgment of the Dead. ${ }^{10}$

The Coffin Texts give an insight into the ritual enactment of the Judgment of the Dead in the form of liturgical recitation. The liturgical recitation connects the vindication of the deceased in the Judgment of the Dead with the process of embalming and mummification. Guilt, sin, and accusation are treated as decay and impurity and also as harmful substances that should be eliminated. By removing these harmful substances, the deceased is vindicated. With this concept, removing the decay and the impurity is described by Assmann as the 'physical mummification' and getting rid of sins is described as a 'moral mummification'. ${ }^{11}$ It is likely that after the embalmer finished his work on the corpse, the deceased was then taken to a priest who extended the work of purification and the preservation of the deceased. After the priest's work finished on the mummy, the deceased gains the status of being saH, which could be described as the last stage in the whole mummification process and in which the deceased undergoes the Judgment of the Dead after which he becomes one of the followers of Osiris. This ritualised model of the Judgment of the Dead differs from the model which occurs in BD chapter 125. In this model, the deceased is not plaintiff but he is a defendant. He has to vindicate himself in front of the judges and to recite a long list of transgressions and testify that he has not committed them. His heart was weighted against the feather of Maat. If he is found guilty he would be eaten by a monster, which is here the personification of Seth or the second death described above, but here the monster amam did not stand for evil as Seth but defend against evil. ${ }^{12}$ The two different ways of dealing with the Judgment of the Dead are found on the lid and case of the inner coffin of PA-dj-jmn. The ritualized model of the judgment is depicted on the lid of the inner coffin of PA-dj-jmn, while the model of the judgment common in BD chapter 125 is found on the case of the same coffin.

\section{The ritual of the Judgment of the Dead on the lid of the inner coffin of PA-dj-jmn}

The main scene is the bier of Osiris, where Isis and Nephthys are represented near the feet and head of this bier, and Horus is hovering over Osiris -his father - body. This ritual scene alludes to overcoming death and the announcement of Osiris as king of the underworld. ${ }^{13}$ The depiction of Osiris and the two goddesses can be compared with the scenes in which Isis and Nephthys attend the mummification of Osiris as occurs in the vignettes of Book of the Dead Chapter $151 .{ }^{14}$ Isis and Nephthys are also associated with the coffin ends during the Middle Kingdom. By their association with the coffin ends, the decorations depict the deceased instead of Osiris, who is resurrected in the place of embalming. ${ }^{15}$ The two goddesses' role is acted by two priestesses, who sit towards the deceased's head and feet. On the coffin of Heqata, for instance, Isis and Nephthys are depicted towards the head and feet, accompanied by a text in which they give food for the deceased Heqata. The ornamental text, for instance, towards the coffin's head reads;

'An offering which the king and Osiris give: an invocation offering consisting of bread, beer, and a thousand of head cattle, birds and textile near Isis and Nephthys for the able Heqata, vindicated' ${ }^{16}$

The two goddesses attend mummification; they also mourn the deceased, and recite glorifications for him or her. ${ }^{17}$ In the mentioned text of Heqata; the two goddesses also provide the deceased Osiris with offerings. This -as will be explained later- is similar to the scene on the lid of PA-dj-jmn coffin.

Willems study on the Middle Kingdom coffins argues that the decorations and texts on these coffins focus on three different aspects: mummification; royalty; and offering rituals. ${ }^{18}$ The mummification occurs on the exterior decoration, where Isis and Nephthys are mentioned on the two short sides as mourners of the deceased. They feature as protecting and attending the deceased Osiris. The same can also be applied to the standard gods or column gods on the outside decorated columns with their speeches, which describe the deceased as a venerated so and so with a god. This 


\section{The Exterior Decorations on the Inner coffin of PA-dj-jmn in Cairo Museum (CG 6082 and}

study analysed the decorations and text columns, and concluded that the gods who are shown on the coffin's cornercolumns must be seen involved in the deceased protection. They protect the deceased and pronounce a judgment. ${ }^{19}$ Similarly, Assmann published the outer coffin of Merenptah. He concluded that the gods at the coffin corners act as coffin protectors, and one of their roles is to pronounce a judgment for the deceased. ${ }^{20}$ Assmann ${ }^{21}$ and Willems ${ }^{22}$ argue that these column gods participated in the night vigil around the deceased bed to bring a deceased Osiris back to life. This overcoming of death also means overcoming Seth and, consequently, a deceased Osiris is vindicated by the gods. When Osiris is vindicated, he becomes king of the underworld, and Horus the king of Egypt. ${ }^{23}$ It follows that the mummification of the deceased on his funerary bier should be considered as his coronation. This is why the head of the lion's bier sometimes carries crowns. The coronation of Osiris and his vindication takes place in the Judgment of the Dead, where he was vindicated against Seth. ${ }^{24}$

The deceased on his bier being attended by Isis and Nephthys, and also Horus is a common theme in texts entitled as setting up the bier. These texts form a liturgy in both the Coffin Texts (spells $1-26)^{25}$ and the Book of the Dead (chapters 169 and 170). ${ }^{26}$ We like to argue that the images depicted on this part of the lid refer to the same ritual themes of resurrecting the deceased Osiris. The scene of Osiris on his bier on the lid of PA-dj-jmn inner coffin is placed under the collar and close to the coffin's front with Isis and Nephthys on the two sides wailing the deceased Osiris. Osiris wears royalty signs, like a crown and a false beard. There are also other royal headdresses and crowns under the bier. These objects under the bier as, Willems argues, are rooted in the Old Kingdom offering lists and also on the object frieze on the Middle Kingdom coffins. The scene is a pictorial rendering of that ritual, which was common in Coffin Texts and the Book of the Dead. What is noticeable here is the role of Horus, who is depicted hovering over the mummy of Osiris as protecting his father. Horus does not only exist on the top of the bier, but he is also depicted on the bier's two sides assisting in his father's -Osiris- resurrection. This role is analogous to his role in CT spell 397, which is a ferryman spell in which the deceased -who is placed in a Horus role-, is ferrying across the Winding Waterway to an area near the eastern horizon to embalm Osiris. Horus is the right heir and successor of his father. The spell reads;

(Deceased) I am one whom his father loves, one whom his father loves greatly! I am one who awakens his father when he is asleep!

(Mahaf) do you say you would navigate to the eastern side of the sky? With what aim will you navigate?

(Deceased) That I may raise his head, that I may lift his brow. ${ }^{27}$

The role played by the son of the deceased places him in the role of the sA.mrj=f (the one beloved to his father), which is not different from the role played by Horus on the coffin's lid. In both-CT spell 397 and the scene on the lid- Horus is travelling in a boat and in front of him is the shrine which represents the aim of his journey. Horus is travelling between two trajectories that may refer to the west and east. After reaching the abode where his father is, Horus is able to resuscitate his dead father Osiris, who will then shine in the sky as the sun god Re. The resurrection of Osiris and escaping death are envisaged as his coronation and in which he assumes the wrrt crown and becomes the ruler of the underworld. ${ }^{28}$ On Middle Kingdom coffins, the mummification of Osiris and escaping the death caused by Seth is also envisaged as a Judgment of the Dead, where Osiris is vindicated against Seth. The Judgment of the Dead in ancient Egyptian ritual texts appears to be incorporated within the journey to Sais, in which a speech is pronounced by Neith. The Great and Small Enneads, the judges who participate in this judgment, are also described as column gods. The vindication of Osiris against Seth took place in the lawsuit of Heliopolis. ${ }^{29}$ This complex of thoughts is referred to in the texts and representations of the journey to Sais. According to the inscriptions of Merenptah, after the mummification process finished Osiris was justified and crowned as king in the presence of the two Enneads and the Two State Chapels. When Osiris reached Sais, his enemies were destroyed. The text columns' gods are mentioned individually, stating their positions surrounding the deceased from all sides. The Ennead features as a court of justice, and they are depicted at the coffin's corners to protect the deceased. ${ }^{30}$ The role of the gods in the court of justice was played by priests attending the mummy. Thus, the journey to Sais probably incorporated Osiris' victory over his enemies and his coronation as a king in the netherworld. ${ }^{31}$ The speeches of the goddess Neith on different parts of the lid hint at the journey of Sais. She appears on the coffin's border as Mother of the God, Eye of Re, and Mistress of the House of Life. The deceased is also described as the Revered or Venerated One with Neith. The inscription of the coffin of Merenptah, described Neith as the mother of the king and the embodiment of the coffin. She addresses her son Merenptah in a long speech where the king is first described inside his mother's - Neith- womb, who represents the coffin itself. The rest of the text deals with the actions taking place in embalmment area, where the rituals are performed by Isis and Nephthys and also the Four Sons of Horus. Then Neith places other gods like Shu, Tefnut, Geb, and Nut to the left and right of the deceased. These deities proclaim Merenptah to be a king, who later appears at the temple of Neith at Sais. This sequence of events -according to Assmann- takes place in the Stundenwachen, the nightly wake before burial. ${ }^{32}$ According to Willems, the gods of the columns in Merenptah inscriptions appear as 'priests playing divine roles'. ${ }^{33}$ The role of Neith as mother of the coffin is complemented by the role of the sky goddess Nut depicted with her outstretched wings on the lid. The speeches of the goddess Neith on the lid allude to a judgment, which is envisaged as a journey taking place to Sais.

On the lid, Isis and Nephthys are depicted on the bier's two sides with Horus on the top. Under the bier, the goddess Nut is shown flanking the bier as if she is carrying it. The Four Sons of Horus are depicted under the two wings of Nut, supporting the sky and attending the bier. Neith and Serqet are shown at the lid's two borders, flanking the 
whole composition. Isis and Neith appear again at the feet with their speeches. Horus, son of Osiris, appears many times on different sides of the lid. The lid middle part is occupied by texts, which mention Osiris, Ptah-Sokar, Neith, Serqet, Hapi, Anubis, and Geb. These deities might form the Ennead mentioned in the lid inscriptions. On the lid, the deceased arrival to the west is envisaged as his crossing to the sky. The necropolis deities also rejoice when he reaches the necropolis where he will not die again with the Ennead. This may allude to the second death mentioned by Assmann, which the deceased would escape by undergoing the Judgment of the Dead, where the Ennead is the jury and protectors of the deceased Osiris. ${ }^{34}$ The presence of offerings around Osiris and the crowns under the bier indicate that Osiris was vindicated and obtained the wrrt crown as a sign for his victory over Seth. The scarab with the sun disc under the collar refers to the sunrise as a sign of victory over the demons of the night. Osiris is described on the lid as the living Osiris 'anx wsjr', which also can be a sign that Osiris is now a live as the ruler of the underworld.

\section{The Case of the Inner Coffin of PA-dj-jmn (CG 6079)}

\section{Exterior Decorations and Texts}

The case's Top and bottom sides are bordered by bands of geometrical ornaments. The decorations on the two long sides of the case enclose four scenes separated from each other by a vertical column of inscriptions bordered by a gate motif. Along the upper edge of the case runs a long horizontal inscription, which begins at the part behind the head and runs on the case's external left side wall, this text reads;

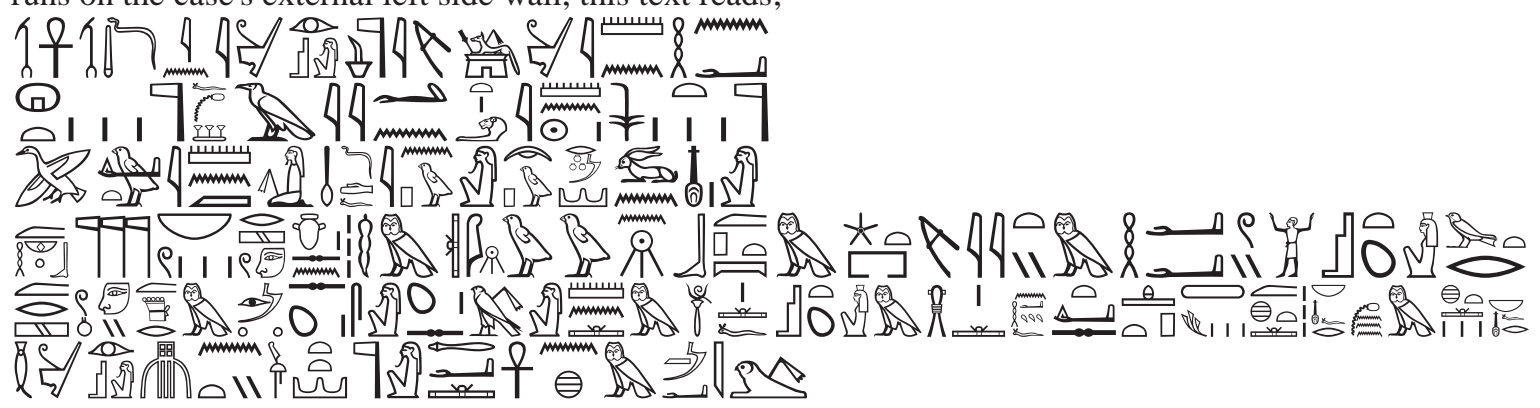

(1) Dd mdw jn wsjr-jt-nTr-mrj-Hry-sStA-n-jmn-Hna-psDt-f-wab-SAj-rmn-HAt-jmn-ra-nswt-nTrw pA-dj-twjmn (mAa)-xrw Dd=f jnpw jaH pw r mAnw wn-nfr m Hb nTrw nbw rSw jb-sn nDm Sw wbn m pt m dwAt mrytj m Haawj Ast wrt $m$ rSw m-Dr mAA=s sA=s Hrw mn iAt=f Ast m sA n Haw=f dj=s Htpw m xt nb nfr wab $m$ xt nb nfr bnr n wsjr xntj jmntt nTr aA anx m mAa axm

Speech by Osiris, the God's Father, the Beloved, Keeper of the Secrets of Amun and his Ennead, Designated Priest, Front-bearer of Amun, PA-dj-jmn the Justified, he says: Anubis, you Moon at Manu (mountain), Wenennefer is in festival, all the gods of the necropolis rejoice and their hearts are happy, Shu who shines in the sky and in the Netherworld, the Beloved, is in joy, and Great Isis is in joy, when she sees her son Horus set in his office. Isis is protecting his limbs, that she may give offerings of every good and pure thing, of every good and sweet thing, to Osiris Foremost of the West the Great God, truly living, Divine Image.

\section{The scene behind the head}

The part behind the head is decorated with a standing figure of a goddess with outstretched and upraised arms. The scene is bordered by two vertical columns of texts. The text on the left reads;

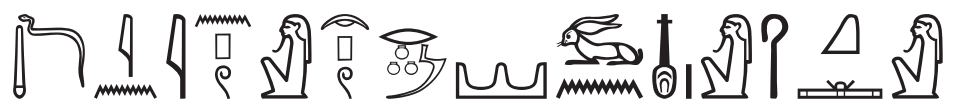

Dd mdw jn jnpw r mAnw wnn-nfr HqA

A speech by Anubis-Who-is-on-the-Mountain, Wennenefer the Ruler.

The text on the right reads;

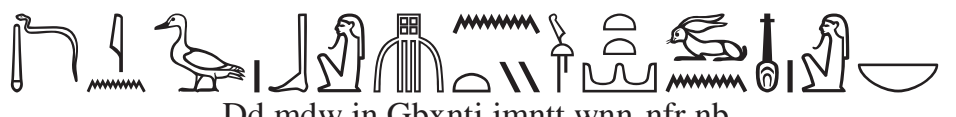

Dd mdw jn Gbxntj jmntt wnn-nfr nb

A speech by Geb Foremost of the West, Wenennefer the Lord 

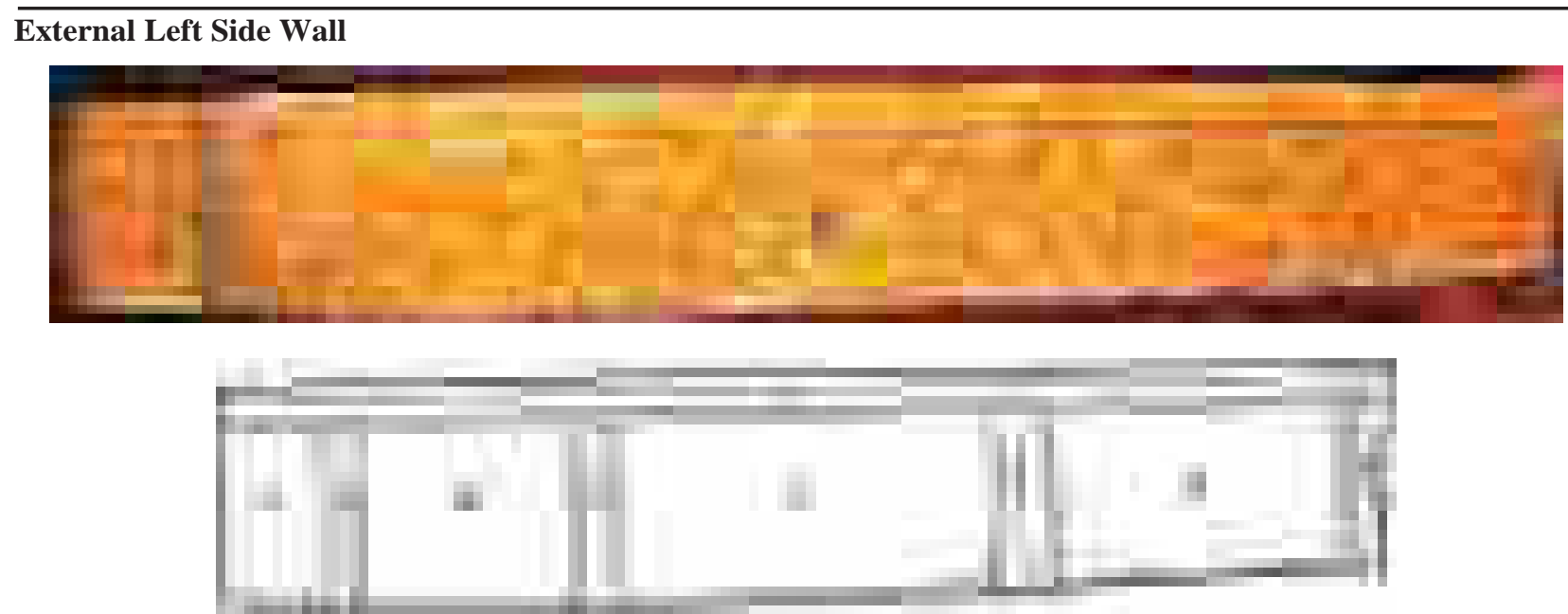

Fig.2 External left side wall of the case of the inner coffin of PA-dj-jmn (photograph courtesy of the Egyptian Museum in Cairo) and a drawing by the authors showing the distribution of the scenes and texts on the external left side wall

\section{Scene 1 near the head (A)}

The first scene on the external left side wall at the head end shows - on the right hand side- the fetish of Abydos. In front of the fetish an inscription, reads;

wsjr nb jmntt wnn-nfr HqA

Osiris Lord of the West, Wenennefer, the Ruler

The fetish is accompanied by imj-wt. Before these two emblems the deceased stands upon a Hb sign pedestal, and stretches his hand towards the two emblems. Behind the standing deceased figure, a serpent with a beard and human legs exist. Behind the serpent stands a lotus flower with a human head. There are also six squatting figures facing the lotus stem. The two upper figures with jackal heads, the middle one with baboon head, and the lower with donkey-head represented frontally. A column of inscriptions separates this scene from the next, and reads;

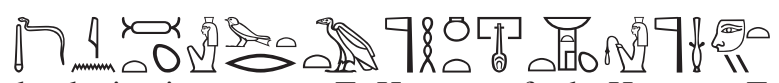

(2) Dd mdw jn njt wrt mwt nTr Hnwt pr-nfr nbt-Hwt snt-nTr xnty

A speech by Neith, the Great, Mother of the God, Mistress of the Beautiful House, and Nephthys, the God's Sister,

\section{Scene 2 near the shoulders $(B)$}

Foremost of

The scene on that side shows the famous cosmological composition of creation. Geb is shown lying on the floor, and his body is covered with reeds. He has a bent beard and Maat feather on his head. Above Geb is the naked sky goddess Nut bent on the tips of her hands and feet, and her body is studded by stars. Between Geb and Nut, Shu is standing dressed in a royal garment holding the solar barque with his upraised arms, where there is a small squatting headed falcon wearing the Atef crown. On both sides of Shu, there are two standing falcons on the emblem of the west. On both sides of Shu and in front of the two falcons there is a text reads;

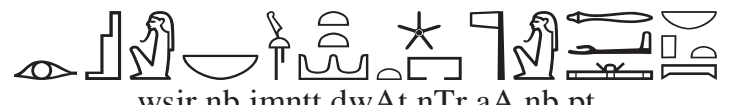

wsjr nb jmntt dwAt nTr aA nb pt

Osiris, Lord of the West and Duat, The Great God, Lord of the sky

Isis and Nephthys stand on the right and left side of Nut figure. They stretch their hands in a gesture of protection, both stands on a smA-tAwj symbol. The inscriptions in front of Nephthys read;

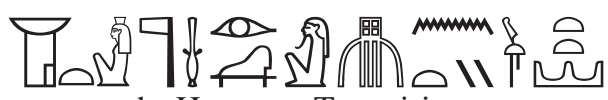

nbt-Hwt snt-nTr xntj-jmntt

Nephthys, the God's Sister (of) Osiris Foremost of the West

The inscriptions in front of Isis read;

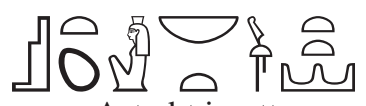

Ast nbt jmntt

Isis Lady of the West

The scene is separated from the next one by a vertical column of inscriptions, and reads; 


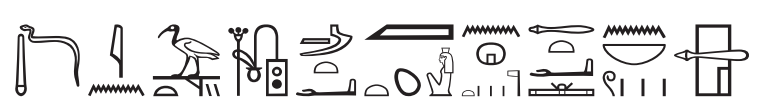

(3) Dd mdw jn DHwtj sS mAat n psDt aAt n nbw Hwt-aA

A speech by Thoth the Scribe of Maat of the Great Ennead and of the Lords of the Great Temple (of Heliopolis).

\section{Scene 3 near the hips $(C)$}

The deceased is introduced to Osiris. The scene is divided into two parts; the first shows Osiris sitting on a throne. He wears the composite Atef crown and holds all the royal signs of anx, scepter, and flagellum. The inscriptions in front of him read;

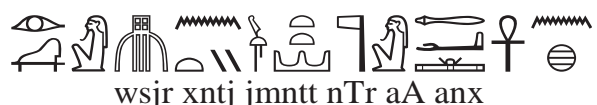

Osiris, Foremost of the West, The Great God, the living One

Thoth is shown as the divine scribe with a head of an Ibis holding a palette and a pen in his hand and records the events. In front of him is an inscription, which reads;

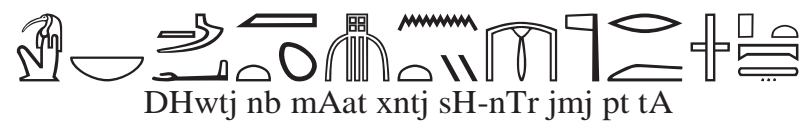

Thoth, Lord of Maat, Foremost of the Divine Booth, which is in sky and earth

The scene's second part shows the deceased with three deities approaching Osiris. There is a caption in front of the second part, and reads;

$$
\text { prjt dwAt nTr aA }
$$

She who emerges (from) the Duat of the Great God

The deceased is escorted by a lioness-headed goddess and followed by Isis with a head of a cobra. Behind Isis is Hapi with the head of an ape. The lioness-headed goddess and Isis hold the hands of the deceased PA-dj-jmn as if they are presenting him to Osiris, and Duamutef stands behind. The vertical column of inscriptions which separate this scene from the next is a speech by Duamutef, and reads;

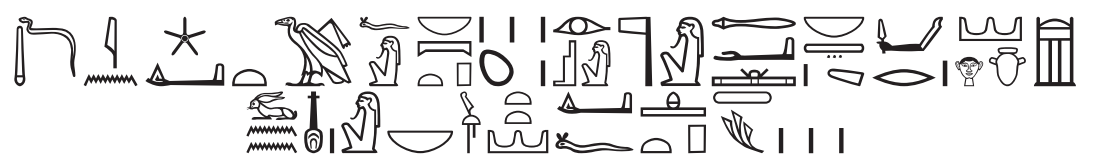

Dd mdw jn dwA-mwt-f nb pt sA wsjr nTr aA nb tA Dsr Hrj-jb jtrt wnn-nfr nb jmntt dj=f Htpw

A speech by Duamutef, Lord of the Sky, Son of Osiris, the Great God, and Lord of the Sacred Land, Who is in the Middle of the shrine of Wenennefer, Lord of the West, that he may give offerings.

\section{Scene 4 near the legs $(D)$}

On the scene's left side behind the deceased, there are four recumbent celestial cows and a standing bull, represents the vignettes of Book of the Dead Chapter $148 .{ }^{35}$ The deceased is shown kneeling in the middle, and drinking from the water poured by the goddess standing in front of him. Behind the deceased, a falcon stands on the emblem of the west with a sun disc and two feathers on the head. There is a caption in front of the falcon and above the head of the kneeling deceased, and reads wsjr nb jmntt (Osiris Lord of the West). The goddess is given two different epithets; nbt Hwt snt$n \operatorname{Tr}$ (Nephthys Sister of the God), and behind her there is a caption which reads Ast xntj jmntt (Isis Foremost of the West). Behind the goddess, there is a large sacred sycamore tree, below which is a small bA bird with human hands holding anx signs in adoration gesture. There is also a squatting jackal-headed mummiform figure on the tree's other side. The two vertical columns of inscriptions, which separate this scene from the next read;

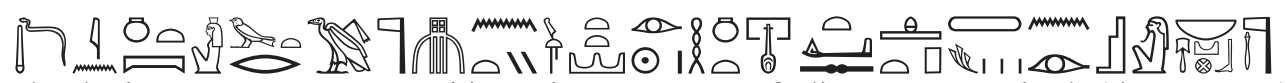

Dd mdw jn nwt wrt mwt nTr xntj jmntt jrt ra Hnwt pr-nfr dj=s Htpw n wsjr nb AbDw nTr aA

A speech by Nut, The Great, Mother of the God Foremost of the West, Eye of Re, and Mistress of the Beautiful House, that she may give offerings to Osiris, Lord of Abydos, the Great God.

\section{The External Right Side Wall (Fig. 3)}

The arrangement of the scenes and texts on that side are identical to the ones on the left side wall. The inscriptions on the upper side read; 


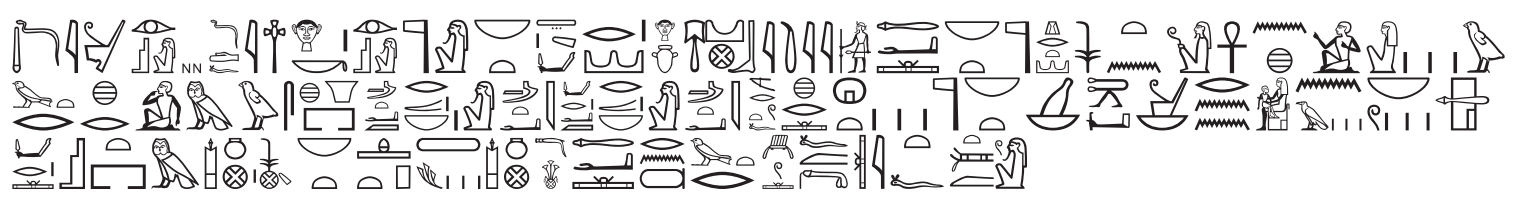

(1) Dd mdw jn wsjr NN Dd=f jnD Hr=k wsjr nTr nb tA-Dsr Hrj-jb AbDw jTj aA nb Xrt-nTr nswt anxw mrj.tw=f xr psDt nbt HDt iTi dSrt rnn ntjw nbw Hwt-aAt wrt xr m wsxt mAat r-gs nb mAat Dsr mAa r-gs nb mAat Dsr st $m$ iwnw Smaw nbt Htpw jwnw mHj aA rn wrt Aw=f m bAH jt=f jtmw

A speech by Osiris NN he says: Hail to you Osiris, the God and Lord of the Sacred Land who dwells in Abydos, Great Sovereign, Lord of the Necropolis, the King of the Living who is beloved by the Great Ennead, Lord of the White Crown who takes possession of the Red Crown, who nurses all those of the Great Mansion! He who speaks in the Hall of Maat beside the Lord of Maat, truly sacred beside the Lord of Maat, Sacred of Seat in Southern Heliopolis, Lord of Offering in Northern Heliopolis, Great of Name, may his offering be much in the presence of Atum.

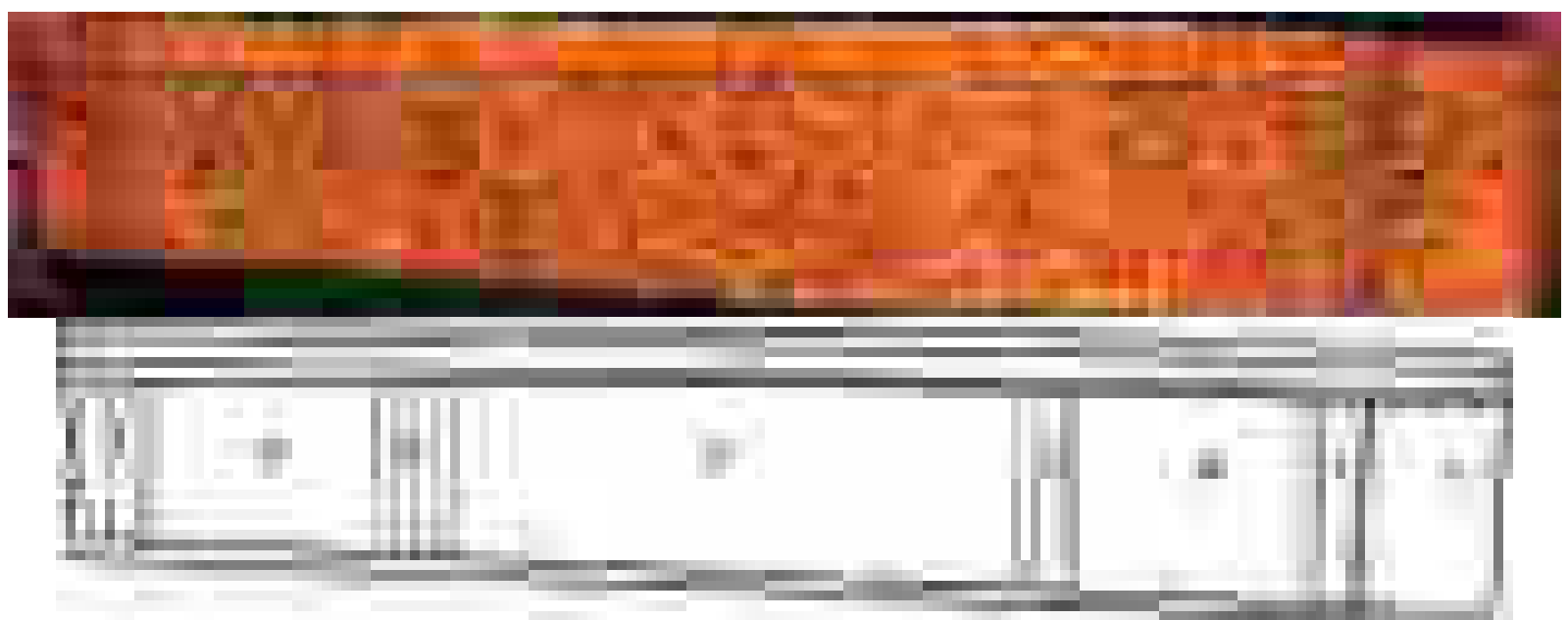

Fig. 3 External right side wall of the case of PA-dj-jmn inner coffin (photograph courtesy of the Egyptian Museum inCairo) and a drawing by the authors showing the distribution of the scenes and texts on the external right side wall

\section{Scene 1 near the head (A)}

The deceased wears a festive garment and gives offerings to the emblem of Abydos. Behind the deceased, is a kneeling figure of a goddess in adoration gesture. She is described as;

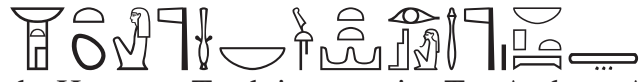

nbt-Hwt snt nTr nb jmntt wsjr nTr aA nb pt tA

Nephthys, God's Sister, Lady of the West, Osiris the Great God, Lord of the sky and earth

She sits on a large nb sign beneath which are two wDAt eyes. A table of offerings and a small squatting figure with a head of a jackal is depicted in front of the deceased. This scene is separated from the next by a vertical column of inscriptions, which reads;

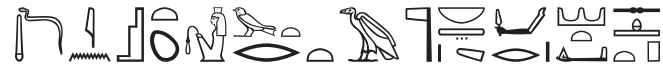

(2) Dd mdw jn Ast wrt mwt nTr nb tA Dsr dj=s Htp

A speech by Isis the Great, Mother of the God, Lady of the Sacred Land, that she may give offering

\section{Scene 2 near the shoulder $(B)$}

Osiris is shown seated on a two steps throne resting on nb sign. The god is shown with all signs of royalty. The throne steps are decorated with two mythical animals with ram's body and head of a crocodile. The two mythical creatures seem to guard a door. Two falcons are depicted standing on $\mathrm{Hb}$ sign before and behind of Osiris, and wearing the crowns of Re-Horakhty with cobra. The two falcons are accompanied by inscriptions read; wsjr nb jmntt 'Osiris Lord of the West'. Beneath the two falcons, two bA birds are in adoration gesture holding anx signs in their hands and make offerings to Osiris. A caption behind the bird to the west and before the seated figure of a deity with an ape head, of which reads $\mathrm{dj}=\mathrm{f} \mathrm{Htpw} \mathrm{'He} \mathrm{may} \mathrm{give} \mathrm{offerings'.} \mathrm{Isis} \mathrm{is} \mathrm{bordering} \mathrm{the} \mathrm{right} \mathrm{side,} \mathrm{and} \mathrm{Maat} \mathrm{is} \mathrm{in} \mathrm{the} \mathrm{left.} \mathrm{They} \mathrm{are}$ depicted adoring the seated figure of Osiris. The scene is separated from the next by a vertical column of inscriptions, which reads; 
(3) Dd mdw jn njt wrt mwt nTr xntj jmntt dj=s Htpw ${ }^{36}$

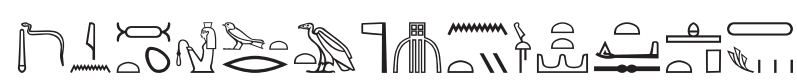

A speech by Neith the Great Mother of the God Foremost of the West that she may give offerings.

\section{Scene 3 near the hips $(C)$}

The scene shows the Judgment of the Dead, where Osiris sits on a throne, and a speech inscribed before him, which reads;

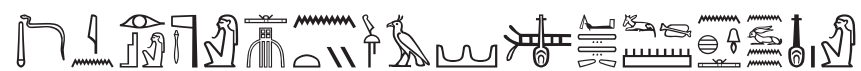

Dd mdw jn wsjr nTr aA xntj jmntt nfr-tm xwj tAwj iwa mnx n wnn-nfr

A speech by Osiris, the Great God, Foremost of the West, Nefertem, Protector of the Two Lands and Potent Heir of Wenennefer. ${ }^{37}$

In front of Osiris Thoth stands wearing the Atef crown and extends his hands while speaking to Osiris. There is a speech in front of Thoth reads;

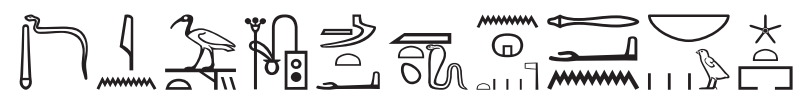

Dd mdw jn DHwtj sS mAat n psDt aA n nbw dwAt

A speech by Thoth, Scribe of Maat of the Great Ennead of the Lords of the Underworld

\section{Behind Thoth is a caption reads;}

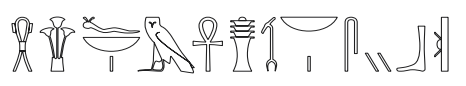

$\mathrm{sA} \mathrm{HA}=\mathrm{f} \mathrm{nb} \mathrm{m}$ anx Dd wAs nb $\mathrm{s}(\mathrm{n}) \mathrm{b}$

Protection behind him with all life, stability, dominion and health

Behind Osiris, Isis stands in adoration gesture. In the center, the balancing of the heart is represented. Anubis is represented with a wide open mouth, and behind him there is a coiled snake. The other side of the balancing has a scene in three registers; the first shows a seated lion with two serpents in his mouth and a cobra on its forehead. The second shows three squatting figures with jackal, human and falcon heads. The third register shows a vulture and a cobra standing opposite to each other on $\mathrm{Hb}$ sign. On the right side of the balance the deceased is shown standing with upraised arms as a sign of his triumph. His head is bald with a headband, and adorned by unguent cone, ${ }^{38}$ and two lotus buds. There are two cobras and a winged wDAt eyes over the two cobras. a wDAt eye is also depicted above the deceased head. Before and behind the deceased, there are two falcons standing on the West emblem, and fronted by two cobras. The left side falcon is named as Ast (Isis). The scene is separated from the next one by a vertical column of inscriptions, which reads,

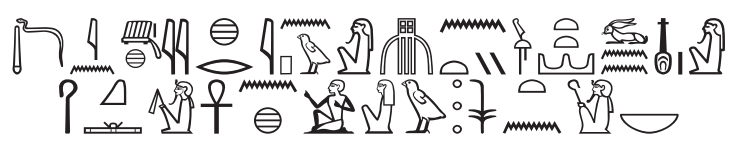

(4) Dd mdw jn jmAxj xr jnpw xntj jmntt wnn-nfr HqA anxw nswt nb ${ }^{39}$

A speech by the Revered One with Anubis, Foremost of the West, Wenennefer Ruler of the Living, King and Lord

\section{Scene 4 near the leg $(D)$}

The deceased is depicted kneeling and making offerings to Hathor who emerges from the western mountains. In front of the deceased is a text giving the names and titles of the goddess, as follows;

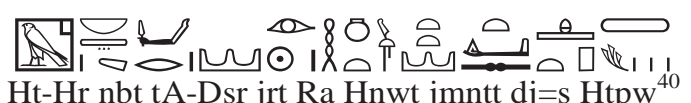

Hathor Lady of the Sacred Land (Necropolis), the Eye of Re and Mistress of the West, that she may give offerings

Above the inscriptions there are seven squatting figures with different heads -from right to left- of cobra, ram, donkey, human, jackal, falcon, and an ape. Behind the cow there is a representation of a tomb carved in the mountain from which Hathor emerges. On the tomb's entrance, the name of Wsjr is written, and above is a winged solar disc. On the upper part, there is a small pyramid with inscriptions read;

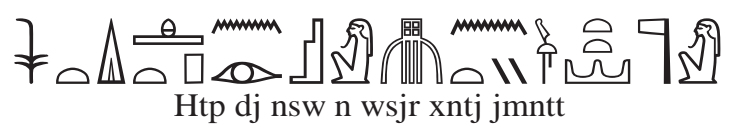

An offering that the King gives to Osiris Foremost of the West 
On the last part of this case's side, an inscription written in vertical columns, which read;

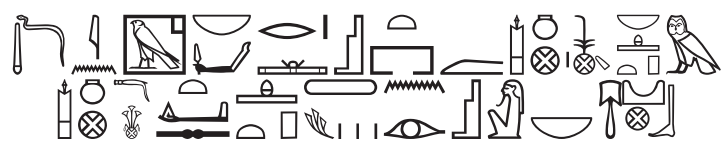

(5) Dd mdw jn Ht-Hr nb Dsr st m jwnw Smaw nb Htp m jwnw mHw dj=s Htpw n wsjr nb AbDw

A speech by Hathor, Lady of Sacred of Seat in Southern Helipolis and Lady of Offering in Northern Heliopolis, that she may give offerings to Osiris, Lord of Abydos

\section{The Case of the Inner Coffin as the Hall of the Judgment of the Dead}

Images and texts on the exterior of the case of PA-dj-jmn inner coffin are deeply connected with the Judgment of the Dead. As mentioned above, the Judgment of the Dead as a ritual was incorporated in the journey to Sais, where the goddess Neith plays a prominent role. She speaks to her son who is pictured inside the coffin as a mother and also as a protector. Here on the exterior of the inner case, the goddess appears more than once with different speeches. The deceased on the lid is described as a Venerated One with Neith. At the bottom edge of the lid, there is a speech for the goddess, in which she is described as a mother of the king and Lady of the West. She also occurs at the lid border as a mother, who gives the deceased thousand different offerings. Like Isis, Nephthys, and Serqet, Neith protects the Four Sons of Horus. These different deities on the lid -as argued above- pronounce their speeches in the night before burial in embalmment area.

\section{Conclusion}

It can be concluded that the lid of PA-dj-jmn inner coffin represents the ritualized model of the Judgment of the Dead, which was designed on the lawsuit between Seth and Horus. Decorations on the case's exterior walls represent the other model of the Judgment of the Dead, where the deceased's heart is being weighed on a scale against the feather of Maat. The existence of the judgment two models on the lid and case of PA-dj-jmn inner coffin might also be related to the deceased's desire to escape the two phases of death described above. The recurrence of rebirth and resurrection scenes on the inner case's two sides might be connected with the deceased first and second death. Like the ancient Egyptian rituals texts, ${ }^{41}$ the images on the inner coffin of PA-dj-jmn do not refer to a coherent set of rituals. However, the scenes on the coffin are repetitive and draw on different metaphors. It is known that the ancient Egyptian ritual texts survived in textual corpus and the focus is on the speaking of the word, and which are highly allusive to their explanation to the myth to accompany the ritual action. ${ }^{42}$ In the coffin of PA-dj-jmn the images seem to play the same role of the word or more precisely the spoken word. They are also highly allusive to the myth to accompany the ritual action. It is impossible to predict that the image was placed on the coffin sides without having ritual functions. We have the illustrated versions of rituals on the sides of the coffin, and what is missing is the spoken word which accompanied the performance of such rituals. These images can be described as the ritual actions which should have been accompanied by recitation of ritual texts. The evidence for the existence of such spoken words to accompany the ritual is the use of the Dd mdw formula on different parts of the coffin. Ritual texts intended for recitation are designated by the formulaic heading Dd mdw (saying of words). ${ }^{43}$ Images on the coffin act as a service-book used by in the course of performing ritual, and which also does not contain a coherent set of images but discrete units of ritual images rather than continuous ritual images. The resurrection of Osiris and his coronation are all represented on the coffin sides as images not texts as they were on Middle Kingdom Coffin Texts. These images of death and resurrection process are recurrent on the coffin sides. Images also show how the enactment of the myth in ritual set a continuous process in motion which was necessary for the deceased to share in the daily cycle of death and resurrection of both Re and Osiris. The deceased within the coffin has several roles to play in the myth of death and resurrection of Osiris. He is Osiris who is resurrected by the aid of Isis, Nephthys, and Horus. In his journey to the netherworld near the eastern horizon, he plays the role of Horus the son of Osiris who travels towards his father's shrine to embalm him and bring him back to life. ${ }^{44}$ In this case, the deceased takes the role of the father Osiris and Horus is his son. The mummification and resurrection of the deceased father Osiris was imagined as his coronation. As a result, Osiris became the king of the underworld and Horus the king of Egypt. ${ }^{45}$ The cycle of death and resurrection was also incorporated in the daily cycle of the day and night journeys of Re in the sky. This explains the existence of the images of boat, scarabs, and sun discs on the coffin's different sides. 


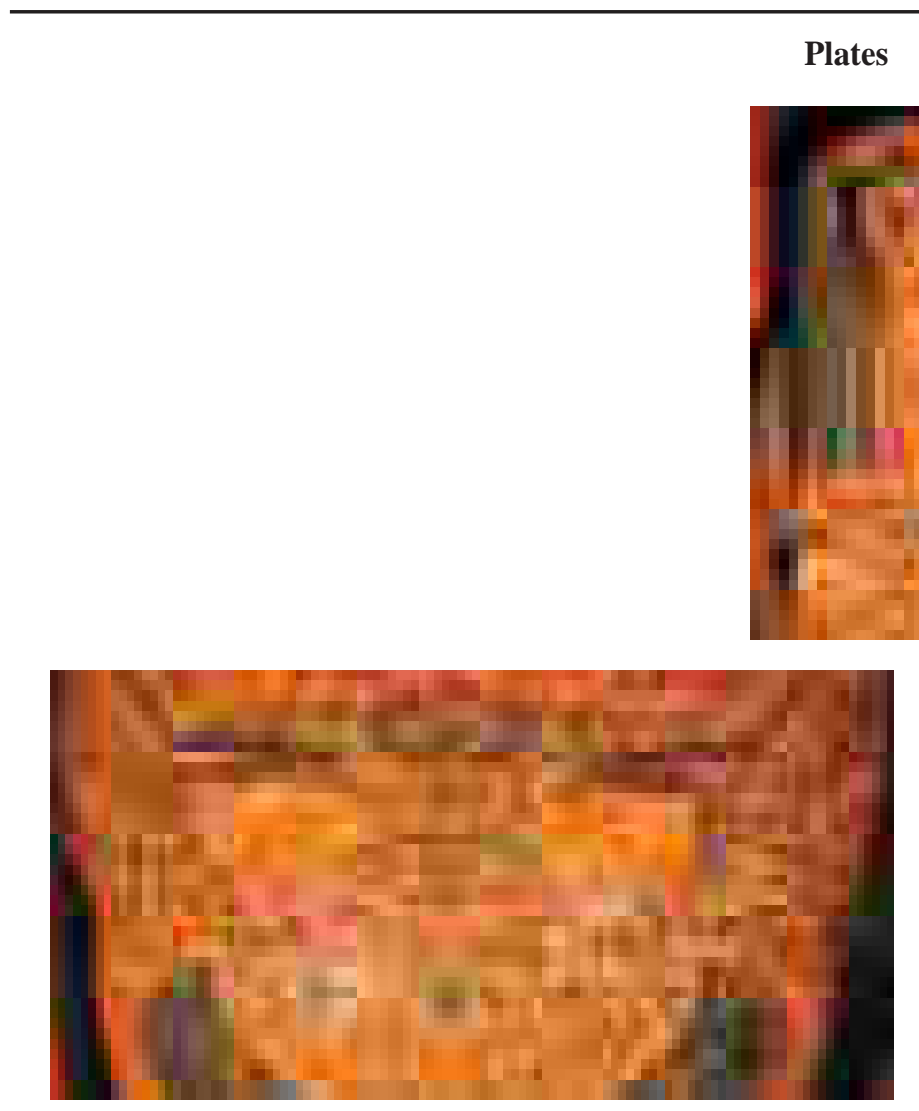

(A1-A-5)

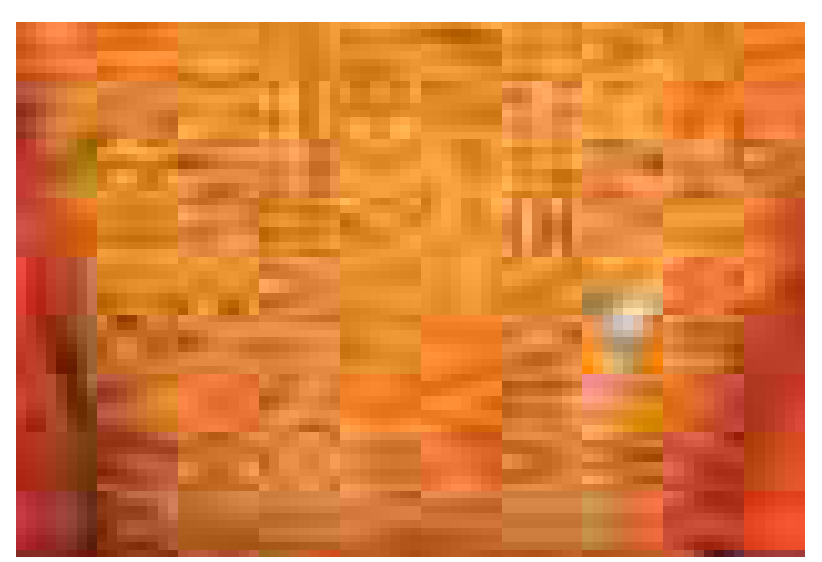

The Lid Decorations

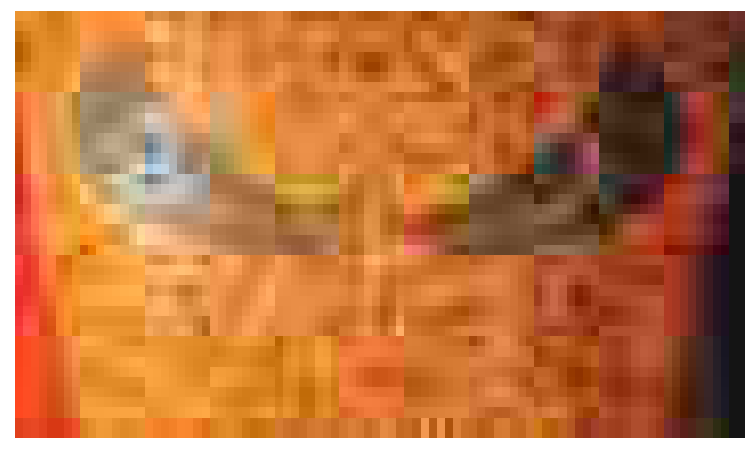

(B1-B3)

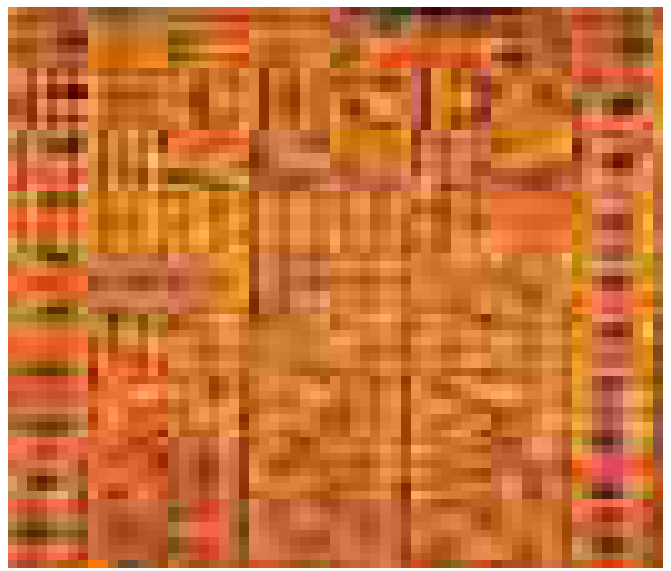

The lower part (scenes No. 1-15 and B-F) 
Case Decorations

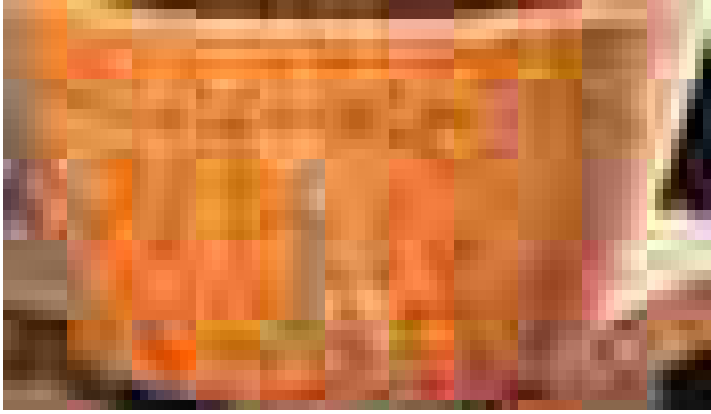

Scene behind the head

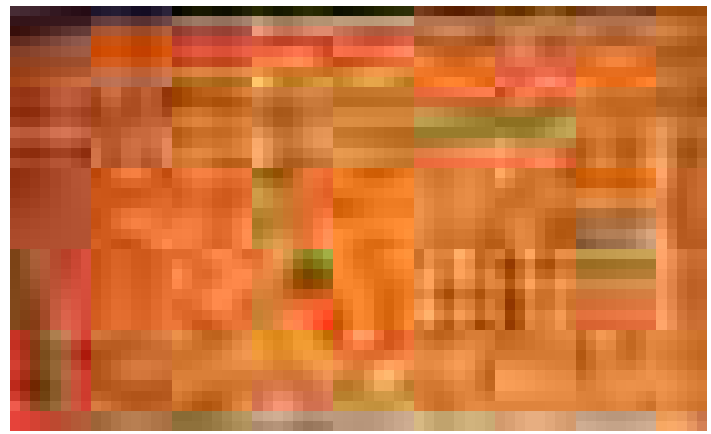

(A)

Left side Wall

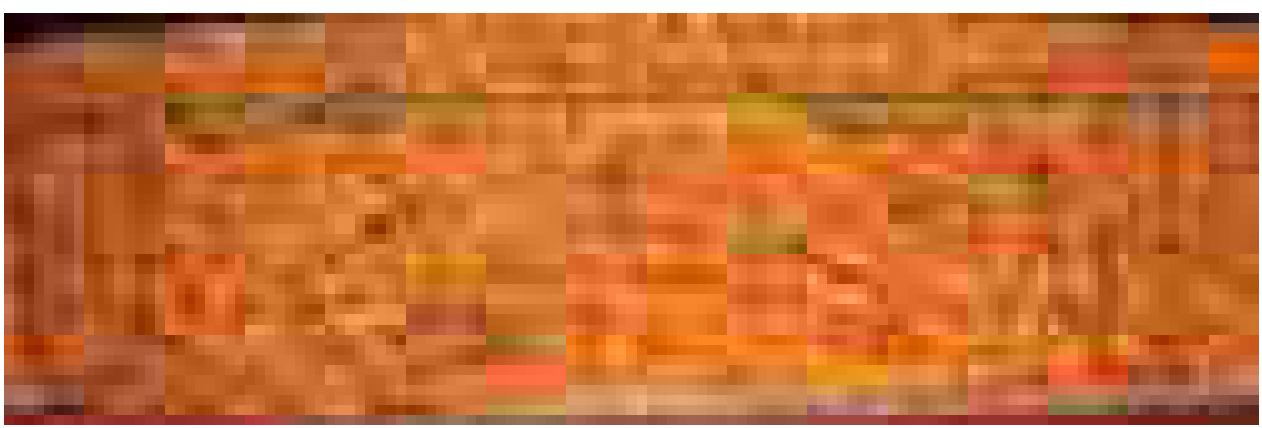

(B)

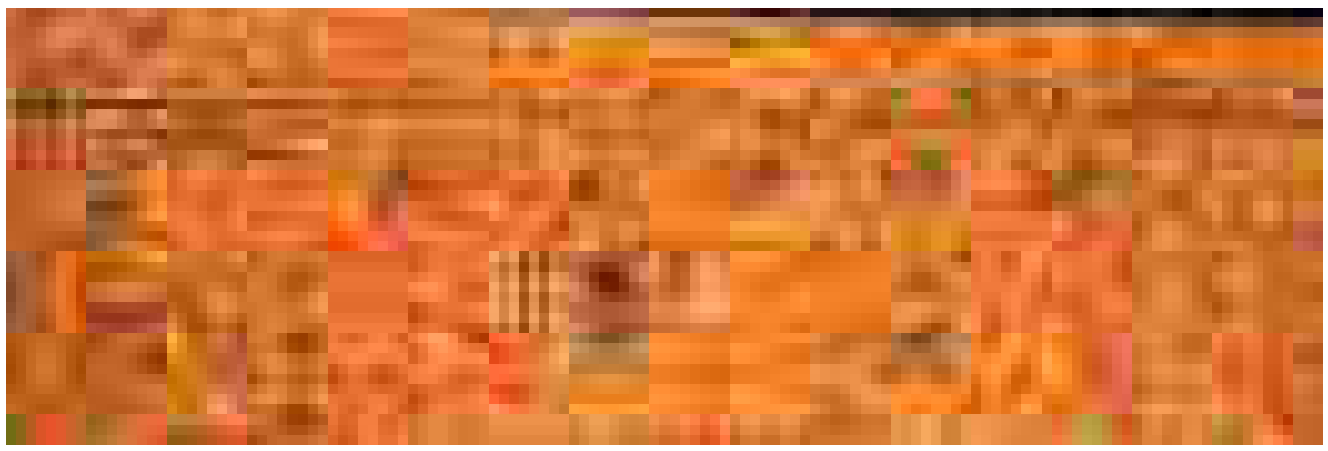

(C)

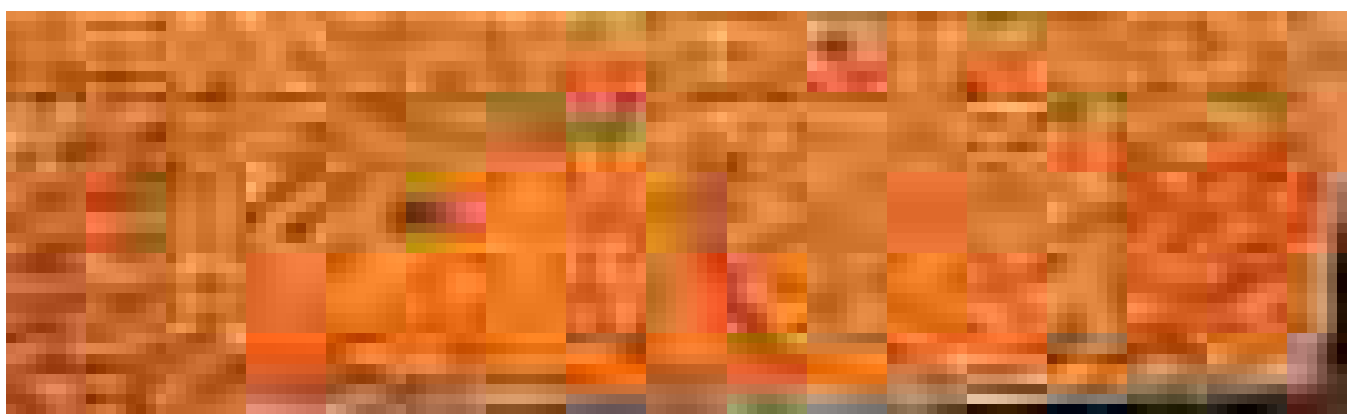

(D) 
Right side wall

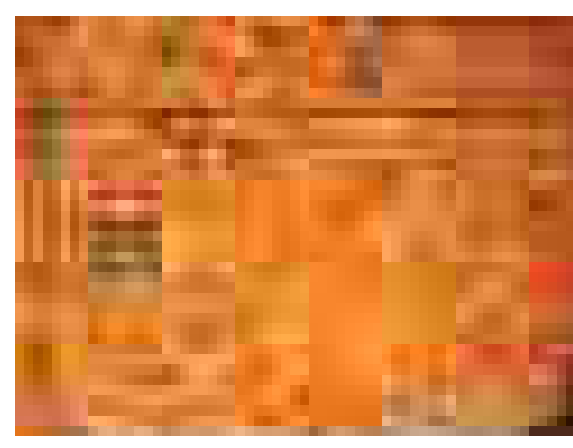

(A)

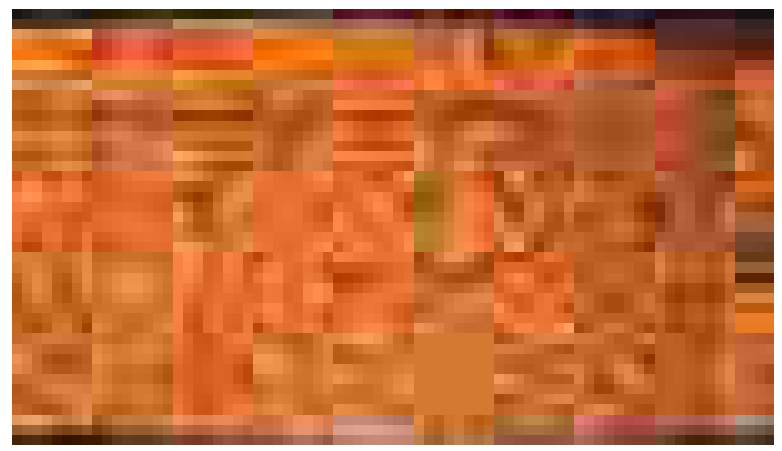

(B)

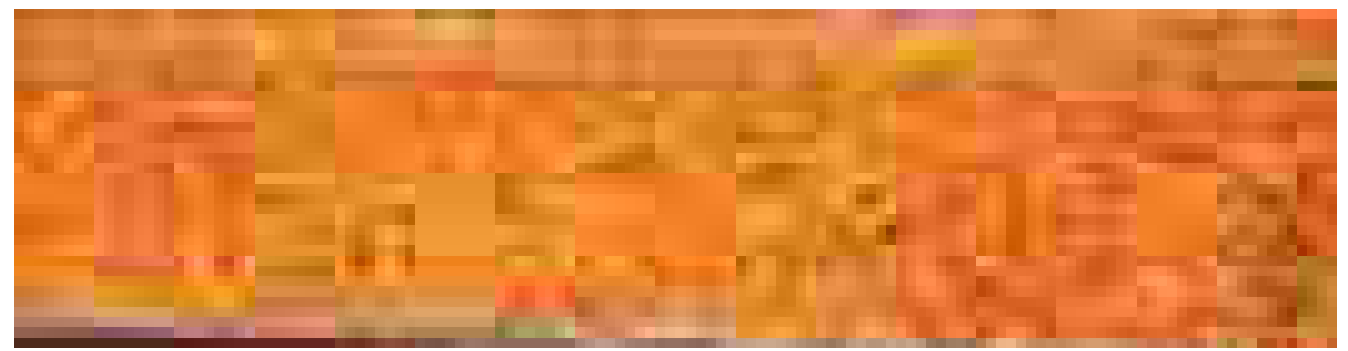

(C)

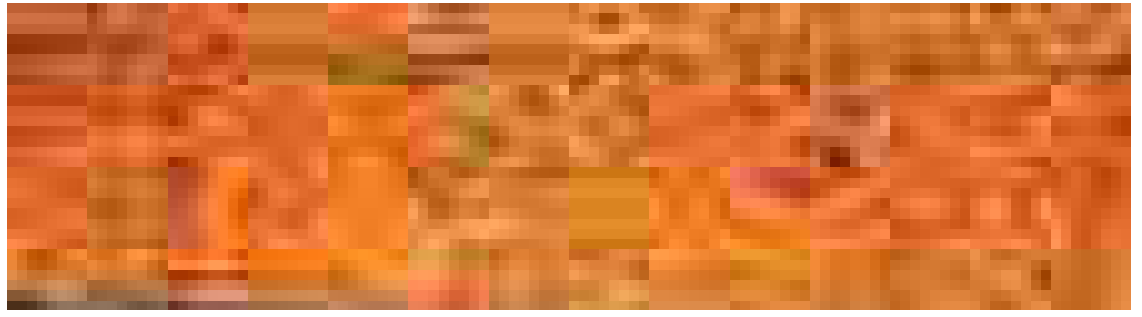

(D)

\section{References}

${ }^{1}$ Niwinksi, A. (1999), Catalogue General of Egyptian Antiquities of the Cairo Museum Numbers 6069-6082, The Second Find of Deir El-Bahri (Coffins), $2^{\text {nd }}$ vol. $1^{\text {st }}$ Fascicle, Cairo, pp. 9-18

${ }^{2}$ Ibid, p. 9

${ }^{3}$ The numbers and letters refer to the scenes on the lid as shown in the drawing

4 Taylor, J. (2006), 'The Coffin of Padiashaikhet', in: Sowada, K.N. and B.G. Ockinga (eds), Egyptian art in the Nicholson Museum, Sydney, Sydney, p. 274

5 Ibid, p. 274

${ }^{6}$ Niwinski (1999), The Second Find of Deir El-Bahri, pp. 9-10

${ }^{7}$ Sethe, K. (1908-1922), Die altägyptischen Pyramidentexte, Lepizig, spell 273=Pyr. § 396a-397c.

${ }^{8}$ Taylor, J. (2003), 'Theban Coffins from the Twenty-second to the Twenty-sixth Dynasty: dating and synthesis of development' in: Strudwick, N. and J. H. Taylor (eds), The Theban Necropolis: Past, Present and Future, London, p.106.

${ }^{9}$ Assmann, J. (2005), Death and Salvation in Ancient Egypt, translated from German by D. Lorton, Ithaca and London, p. 73

${ }^{10}$ Ibid, p. 73(B1-B3)

${ }^{11}$ Ibid, p. 74

${ }^{12}$ Ibid, p. 75

${ }^{13}$ The scene is also common on the Theban Papyri of the $11^{\text {th }}$ and $10^{\text {th }}$ centuries; Niwinski, A. (1989), Studies on the Illustrated Theban Funerary Papyri of the 11 and 10 centuries B.C, OBO 86, Freiburg, pp. 143-145 
${ }^{14}$ For the spell 151 of the Book of the Dead, see Lüscher, B. (1998), Untersuchungen zu Totenbuch Spruch 151, SAT 2 , Wiesbaden.

15 Willems, H. (1997), 'The Embalmer Embalmed. Remarks on the Meaning of the Decoration of Some Middle Kingdom Coffins', in: Van Dijk, J. (ed.), Essays on Ancient Egypt in Honour of Hermann te Velde, Groningen, p. 354

${ }^{16}$ Willems, H. (1996), The Coffin of Heqata (Cairo JDE 36418): A Case Study of Egyptian Funerary Culture of Early Middle Kingdom, OLA 70, Leuven, p. 55

${ }^{17}$ Ibid, pp. 55-6; and pp. 89-93

${ }^{18}$ Willems (1997), in: Van Dijk, J. (ed.), Essays on Ancient Egypt in Honour of Hermann te Velde, op.cit., p. 358.

${ }^{19}$ Willems, H. (1988), Chests of Life, Leiden, pp. 141-59.

20 Assmann, J. (1972) Neith spricht als Mutter und Sarg, Interpretation und metrisch Analyse der Sargdecklinschrift des Merenptah. MDAIK 28.2, pp. 127-130.

${ }^{21}$ Ibid, pp. 127-130.

${ }^{22}$ Willems (1988), Chests of Life, op.cit, pp. 141.159

${ }^{23}$ See Assmann, J. and M. Bommas (2002), Altägyptische Totenliturgien, vol. I, Totenliturgien in den Sargtexten des Mitteleren Reiches, Supplemente zu den Schriften der Heidelberger Akademie der Wissenschaften, Philosophischhistorische Klasse 14, Heidelberg, p. 163

${ }^{24}$ Willems (1988), Chests of Life, op.cit, pp. 141-148

${ }^{25}$ Assmann and Bommas (2002), Altägyptische Totenliturgien, op.cit., pp. 54-60

${ }^{26}$ Lüscher (1998), Totenbuch Spruch 151, op.cit

${ }^{27} C T$ V, 78c-81c (spell 397); the translation is after Willems (1997), in: Van Dijk, J. (ed.), Essays on Ancient Egypt in Honour of Hermann te Velde, op.cit., p. 360

${ }^{28}$ Willems (1988), Chests of Life, op.cit., p. 150; Roeder, H. (1996), Mit dem Auge sehen: Studien zur Semantik der Herrschaft in den Toten- und Kulttexten, SAGA 16, Heidelberg, pp. 294-7; Goebs, K. (2008), Crowns in Egyptian Funerary literature, Oxford, pp. 36-7

${ }^{29}$ Grieshammer, R. (1970), Das Jenseitsgericht in den Sargtexten, ÄA 20, Wiesbaden, pp.111-5

${ }^{30}$ Willems (1988), Chests of Life, op.cit, p. 135

${ }^{31}$ Ibid, p. 150

${ }^{32}$ Assmann, J. (1972) Die Inschrift auf dem äußeren Sarkophagdeckel des Merenptah. MDAIK 28.1, pp. 47-73

${ }^{33}$ Willems (1988), Chests of Life, op.cit, 142

${ }^{34}$ Assmann (2002), Death and Salvation, 190

${ }^{35}$ Niwinski, The Second Find of Deir El-Bahri, 17

${ }^{36}$ Niwinski, The Second Find of Deir el-Bahri, 19

${ }^{37}$ Niwinski (1999), The Second Find of Deir el-Bahri, op.cit, p. 19

38 Taylor (2003), in: Strudwick and Taylor (eds), The Theban Necropolis, pp. 101-3. There are also different interpretations applied to the cone and its function for the deceased. It has been argued that it might be an unguent placed on the deceased head to moisturize hair and body. Another interpretation is that the cone is a symbolic and not 'an actual lump of unguent'. For more interpretations on the cone and its use in ritual, exactly, in the Opening of Mouth ritual, see most recently, Padgham, J. (2012), A New Interpretation of the Cone on the Head in the New Kingdom Egyptian Tomb Scenes, BAR 2431, Oxford.

${ }^{39}$ Niwinski (1999), The Second Find of Deir el-Bahri, op.cit, 19

${ }^{40}$ Ibid, p.19

${ }^{41}$ Smith, M. (1993), The Liturgy of Opening the Mouth for Breathing, Oxford, pp. 6-18; Eyre, C. (2002), The Cannibal Hymn: A Cultural and Literary Study, Liverpool, pp. 26-27

${ }^{42}$ Ibid, 27; Willems (1996), The Coffin of Heqata, op.cit, especially pp. 358-61 and pp. 365-8

${ }^{43}$ Eyre (2002), Cannibal Hymn, op.cit, p. 27

${ }^{44}$ Willems (1997), in: Van Dijk, J. (ed.), Essays on Ancient Egypt in Honour of Hermann te Velde, p. 366.

${ }^{45}$ Ibid, p. 358

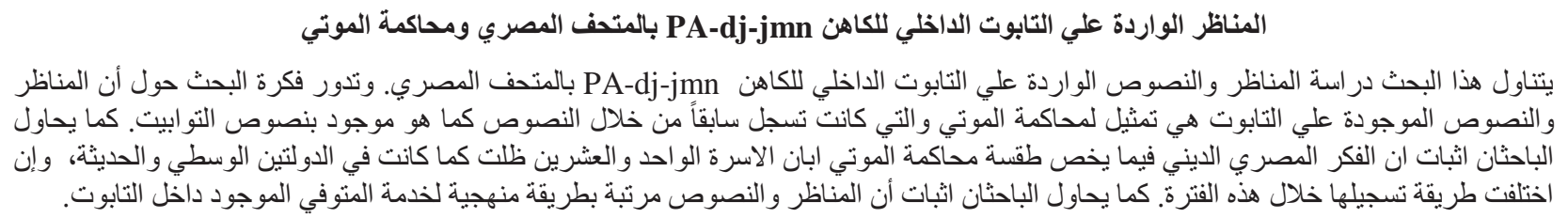

